\title{
Chapter
}

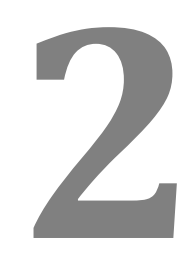

\section{THE IMPRESSIVE ADAPTABILITY OF Acinetobacter baumannii: A PARADIGM OF ANTIMICROBIAL RESISTANCE}

\section{Alejandro Beceiro}

Institute for Biomedical Research of A Coruña (CICA-INIBIC), A Coruña Hospital, Spain 


\section{Contents}

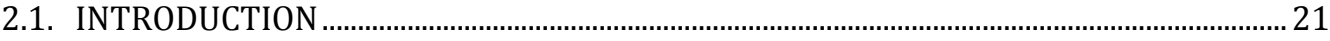

2.2. MECHANISMS OF A. baumannii ANTIMICROBIAL RESISTANCE …..................................... 22

2.2.1. Resistance to $\beta$-lactams ....................................................................................... 23

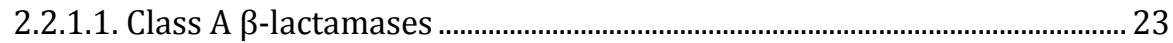

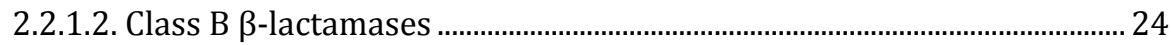

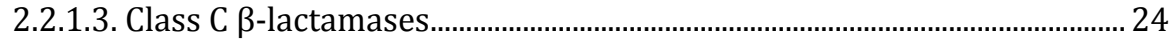

2.2.1.4. Class D $\beta$-lactamases .................................................................................. 25

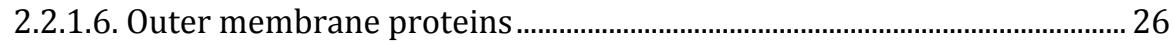

2.2.1.7. Multidrug efflux pumps ................................................................................... 27

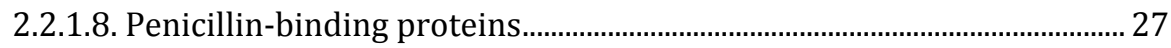

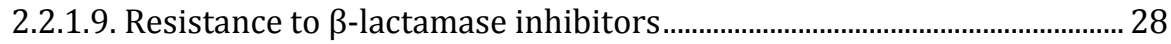

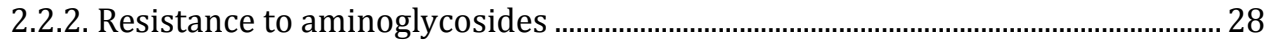



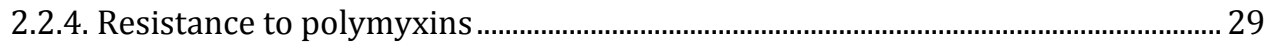

2.3. VIRULENT AND MULTIDRUG-RESISTANT DISSEMINATED CLONES OF $A$.

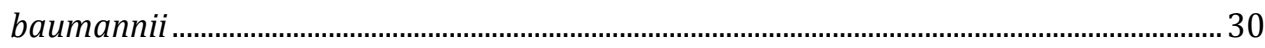

2.4. ANTIMICROBIAL RESISTANCE AND VIRULENCE MECHANISM CO-SELECTION.......... 32



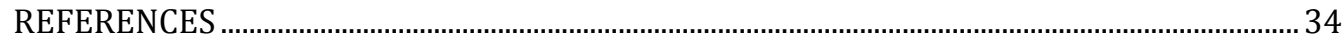




\subsection{INTRODUCTION}

Nosocomial, or hospital acquired, bacterial pathogens frequently obtain and easily develop mechanisms of resistance to multiple antibiotics, presenting significant clinical and economic challenges. Globally, drug-resistant infections are currently responsible for more than half a million deaths each year. By 2050 -unless new solutions are forthcoming- antimicrobial resistance will have caused the deaths of more than ten million people. Related healthcare costs worldwide are projected to be between 300,000 million and more than 1 billion dollars per year [1].

Recently, the World Health Organization (WHO) published a list of "priority" bacterial pathogens demonstrating antibiotic resistance [2]. Among these, Acinetobacter baumannii falls into the "maximum priority" category, and is considered one of the opportunistic pathogens most threatening to global health. A. baumannii's high genetic plasticity allows it to adapt quickly to unfavourable contexts, and easily develop antibiotic resistance (which has led to multiple successive changes in therapeutic strategy). This pathogen has been cited by some authors as a paradigm of multidrug-resistance $[3,4]$.

The increasing frequency of $A$. baumannii isolates that are resistant to antibiotics, such as cephalosporins, imipenem, sulbactam, rifampin, colistin or tigecycline, represents a major challenge when selecting appropriate treatment regimens. In recent years, the frequency of infections and hospital outbreaks caused by strains resistant to most available antibiotics has increased. Virtually all strains of $A$. baumannii are resistant to at least two antibiotic classes [5]. The carbapenems have classically been considered a last resort for the treatment of multidrug-resistant strains, but $A$. baumannii resistance to even this class of antibiotics has increased enormously during the first decade of the $21^{\text {st }}$ century. The SENTRY antimicrobial surveillance program revealed a worldwide increase in imipenem resistance from 34-60 \% in only 3 years (the period from 2006-2009) [6]. In Spain, imipenem resistance rates were even higher, at $83 \%$. Possibly the only effective antimicrobial against this pathogen (resistance rates $<10 \%$ ) is colistin [7], which has clinically-significant shortcomings, such as the high potential for nephrotoxicity and poor bioavailability in the lungs and cerebrospinal fluid $[8,9]$. Antibiotic misuse and insufficient investment in new drug development have resulted in few novel alternatives for the treatment of multidrug-resistant organisms reaching the market over the last two decades. The design and evaluation of new antibiotic therapies is imperative.

While A. baumannii lacks the necessary virulence factors to cause disease in healthy individuals, it can act as an opportunistic pathogen in susceptible individuals (e.g. those with underlying disease). Opportunistic pathogens can produce infection, which can only be prevented by the use of antimicrobial 
therapies. A. baumannii can colonize niches where few other species would survive (e.g. environments with high antibiotic pressure) and can even displace commensal microflora. Antimicrobial resistance can increase the virulence or fitness of certain species in some environments, often helping these species to colonize new niches, such us the hospital environment. This explains why these pathogens are isolated much more frequently than few decades ago. Thus the genetic background of resistant pathogens such as $A$. baumannii allows it to persist in the presence of minimal concentrations of antibiotics or even in their absence [10]. The capacity to develop or acquire resistance and the ability to persist in complicated environments are key factors in explaining the increase in the number of infections in hospitalized patients [10]. Furthermore, in adapting to survival in the presence of antibiotics, species such as A. baumannii and Pseudomonas aeruginosa have evolved to cause greater host damage [11]. Carrying virulence genes also confers some evolutionary advantage during host colonization and infection, favouring resistant strains and providing a plasticity that allows A. baumannii to employ novel strategies in exploring new environments (including providing advantages over commensal microflora).

This review explores intrinsic and acquired resistance mechanisms of $A$. baumannii, with a focus on the main resistance transmission methods known thus far, in order to better understand the plasticity of this species in adapting to survival in the presence of antimicrobials and in a nosocomial environment.

\subsection{MECHANISMS OF A. baumannii ANTIMICROBIAL RESISTANCE}

The most relevant resistance mechanism in Acinetobacter spp. is enzymatic hydrolysis of $\beta$-lactams. However, due to complex resistance development and acquisition systems, multiple resistance mechanisms can coexist in this pathogen [12-14]. The main resistance mechanisms of $A$. baumannii are summarized in Table 1. 
Table 1. Major resistance mechanisms of A. baumannii $[3,15,16]$

\begin{tabular}{ccc}
\hline Antibiotic & Resistance mechanism & Key examples \\
\hline$\beta$-lactams & Enzymatic inactivation & Penicillinases \\
& & Extended spectrum \\
& & $\beta$-lactamases (AmpC, TEM, \\
VEB, PER, CTX-M, SHV) & Carbapenemases \\
& & (OXA, VIM, IMP, NDM-1) \\
& Loss, down-regulation, or & CarO, Omp 33-36, OprD-like \\
& alteration of porins & \\
Alteration of PBP expression & PBP2 \\
Aminoglycosides & Efflux systems & AdeABC \\
& AMEs & AAC, ANT, APH \\
Tetracyclines and & Efflux systems & AdeABC, AdeM \\
tigecycline & Ribosomal methylation & ArmA \\
Polymyxin E & Efflux systems & AdeABC, TetA, TetB \\
(Colistin) & Libosomal protection & TetM \\
\hline
\end{tabular}

\subsubsection{Resistance to $\beta$-lactams}

Inactivation of the $\beta$-lactams is due to the action of the $\beta$-lactamases enzymes, which are grouped into four molecular classes (A-D) following the Ambler's Molecular classification system [17].

\subsubsection{Class $A \beta$-lactamases}

A. baumannii exhibits a wide range of class A $\beta$-lactamases, including Temoneira (TEM), sulfhydryl variable (SHV), cefotaxime-hydrolyzing $\beta$-lactamase (CTX-M), guiana extended-spectrum (GES), self-transferable plasmid from Escherichia coli (SCO), Pseudomonas extended resistant (PER), vietnam extended-spectrum $\beta$-lactamase (VEB), carbenicillin hydrolyzing $\beta$ lactamase (CARB), and Klebsiella pneumoniae carbapenemase (KPC) [18]. However they use to have a minor role in resistance, especially in resistance to carbapenem antimicrobials. Class A $\beta$-lactamases, which are inhibited by clavulanic acid, typically hydrolyse penicillins and cephalosporins more effectively than carbapenems, with the exception of some KPC type enzymes [17].

Some members of this class - such as TEM-1, CARB-4, and SCO- 1 - are narrowspectrum $\beta$-lactamases, whereas other enzymes (e.g., PER-1, TEM-92, CARB10, SHV-5, PER-2, CTX-M-2, CTX-M-15, VEB-1, GES-14, and PER-7) are known 
as extended spectrum $\beta$-lactamases (ESBLs) $[8,19]$. Clinically-relevant ESBLs include CTX-M enzymes, which (due to their transmission via plasmids or integrons) have a high potential for rapid dissemination and could thus produce drug-resistant infection outbreaks [20,21]. Although prevalent among Enterobacteriaceae, ESBLs are less prevalent in Acinetobacter spp., but CTX-M2, CTX-M-43, and CTX-M-15 have been described from Japan, Bolivia and India, respectively [8]. Another relevant ESBL is VEB-1, with reported dissemination in France [22], Belgium and Argentina [8]. Finally, the PER ESBLs, initially observed in $P$. aeruginosa, have been detected in $A$. baumannii in many countries: in Korea, PER-1 is one of the most predominant $\beta$-lactamases $[23,24]$. Additional class A carbapenemases, such as GES-14 and KPC-2, have also been detected in A. baumannii $[25,26]$.

A. baumannii also exhibits other class $A$-lactamases such as the narrowspectrum $\beta$-lactamases TEM- 1 and -2, but they are of lesser clinical significance compared to other resistance mechanisms of Acinetobacter spp. [27,28].

\subsubsection{Class $B$-lactamases}

This class comprises metallo- $\beta$-lactamases (MBLs), which require zinc or another heavy metals for antimicrobial catalysis [17], and are capable of hydrolysing all $\beta$-lactams except monobactams [29]. They exhibit broad-range, potent carbapenemase activity, and are resistant to inactivation by classical inhibitors [30].

MBLs are not the predominant carbapenemases in A. baumannii, but they do contribute to the high carbapenem resistance levels observed in this species. The firsts MBLs isolated in Gram-negative bacilli were imipenemase (IMP)and Verona imipenemase (VIM)-type, in Japan and Italy, respectively [8]. IMP-1 and VIM-2 were the first of this class detected in Acinetobacter spp., in 1998 [31]. Subsequently, VIM-1, VIM-3, VIM-4, VIM-11, IMP-2, IMP-4, IMP-5, IMP-6, IMP-8, IMP-11, IMP-19 and IMP-24 have all been observed in this pathogen [18]. Seoul imipenemase (SIM)- and New Delhi metallo- $\beta$-lactamase (NDM) have also been detected in Acinetobacter spp. [8], although of the SIM-type MBLs, only SIM-1 has been detected [32]. Most recently, NDM-1 [33,34] and NDM-2 [35] have been detected in A. baumannii. The bla $a_{\text {NDM-1 }}$ gene use to be integrated into the chromosome as a transposon, bracketed by two copies of ISAba125, which has facilitated its rapid dissemination [33,36,37].

The MBLs are especially predominant in non-baumannii Acinetobacter spp. Other genomic species (e.g. genomic sp. 13TU and genomic sp. 3) represent the majority of MBL-carrying Acinetobacter spp. isolates [38,39].

\subsubsection{Class $C \beta$-lactamases}

Most Gram-negative bacilli harbour a chromosomally-encoded $\beta$-lactamase, and this is usually a cephalosporinase belonging to class $C$ [40]. Class $C \beta$ lactamases - like classes A and D - are serine-dependent, and display many 
additional specific features, for example an insensitivity to clavulanic acid, and a preference for cephalosporin hydrolysis (although they can also confer resistance to cephamycins and penicillins) [29]. This confers significant therapeutic problems [19]. While the first AmpC $\beta$-lactamase characterized in A. baumannii was from a Spanish clinical isolate in 2000 [41], all strains actually possess intrinsic AmpC cephalosporinases [42] bearing small sequence differences $[43,44]$. In 2005, all Acinetobacter spp. chromosomal cephalosporinases were uniformly designated as Acinetobacter-derived cephalosporinase (ADC) $\beta$-lactamases [45]. ADC enzymes play a pivotal role in the antimicrobial resistance of Acinetobacter spp., especially in isolates carrying an insertion sequence under the control of a strong promoter (ISAba1-like sequence), which usually results in pronounced resistance to ceftazidime $[47,48]$.

\subsubsection{Class $D \beta$-lactamases}

Also known as the OXA-type $\beta$-lactamases (in reference to their preferred hydrolysis of oxacillin) [29], this is probably the fastest-growing class of $\beta$ lactamases with more than 500 reported enzymes [49]. The class D enzymes are organised into three categories, based on substrate specificity: narrowspectrum (e.g. OXA-1 and -10), extended-spectrum $\beta$-lactamases (ESBLs, e.g. OXA-13 and -17), and carbapenem-hydrolysing class D $\beta$-lactamases (CHDLs, e.g. OXA-23 and -24/40) [49,50]. Approximately $50 \%$ of OXA $\beta$-lactamases possess carbapenemase activity [51]. However, due to the multiple mechanisms of antibiotic resistance exhibited by A. baumannii, it is difficult to conclusively determine the relative contribution of CHDLs [52].

Until a decade ago, the most clinically relevant $\beta$-lactamases were the AmpC and extended-spectrum $\beta$-lactamases, but the number of known carbapenemase $\beta$-lactamases has increased in recent years, with CHDLs being especially problematic. Since the description of the first OXA enzyme (OXA-23) in $A$. baumannii in 1993, the number of CHDLs discovered worldwide in clinically-problematic Gram-negative pathogens, such as the Enterobacteriaceae, P. aeruginosa, and (largely) A. baumannii has increased dramatically $[53,54]$. Among the four classes of $\beta$-lactamases, MBLs and CHDLs are the main groups of carbapenemases occurring in A. baumannii, and degradation is the most common mechanism of carbapenem resistance $[55,56]$.

A. baumannii possesses six CHDL families: OXA-23-like, OXA24/40-like, OXA58-like, OXA-143-like, OXA-235-like and OXA-51-like [57-60]. Of these, OXA23-like is the major family of CHDLs, the most disseminated worldwide, and the main source of carbapenem resistance in this pathogen [61]. Other prevalent groups include OXA24/40-like and -58-like. Nearly all strains of $A$. baumannii possess OXA-51-like chromosomal enzymes with weak carbapenemase activity. However, if the gene acquires a strong promoter via 
upstream insertion sequence ISAba1, or is located in a plasmid, it can confer carbapenem resistance [59,62]. The aforementioned insertion sequence has also been described to increase expression of OXA-23 and -58 [63].

The OXA-24/40 CHDL group comprises OXA-24/40, OXA-25, OXA-26, and OXA72 [58]. OXA24/40 was initially identified in Spain in 2000 [64]. Later, OXA-25, OXA-26 and OXA-27 were identified in A. baumannii clinical isolates originating in Spain, Belgium and Singapore, respectively [65]. This group of carbapenemases has now been identified worldwide [18].

OXA-58 was first identified in France, encoded within a plasmid from a multidrug-resistant $A$. baumannii isolate, in 2005 [66]. Since then, it has been found that OXA-58-like CHDL-producing $A$. baumannii isolates are widely distributed [168].

Given that carbapenems have been utilized as last-resort antibiotics for the treatment of multidrug-resistant Acinetobacter infections, the prevalence and plasmid-mediated dissemination of CHDLs are an important clinical challenge, motivating evaluation of potential alternate antibiotics (including $\beta$-lactamase inhibitors, aminoglycosides, tigecycline and polymyxins) in the treatment of such infections.

\subsubsection{Outer membrane proteins}

Although $\beta$-lactamases with carbapenemase activity are the main carbapenem resistance mechanism, porins are also thought to be involved. Their reduced expression plays a role in the resistance to these antibiotics. Few outer membrane proteins (OMPs) have been reported, their functions remain unclear [67], and - compared to other pathogens - little is known about the porins of $A$. baumannii. Indeed, $A$. baumannii exhibits very low outer membrane permeability, with a small number and size of porins relative to other Gram-negative organisms [68]. Several reports describe down-regulated expression of some OMPs, implicating these in antimicrobial resistance $[13,14]$. The major OMP of $A$. baumannii, reported to date, is the heatmodifiable protein $\mathrm{HMP}-\mathrm{AB}$, which exhibits homology with the monomeric OmpA of Enterobacteriaceae and with OMP-F (OprF) of P. aeruginosa [69]. Three additional porins implicated in carbapenem resistance are the 33-36 $\mathrm{kDa}$ protein [70], the $29 \mathrm{kDa}$ protein (CarO: carbapenem resistance-associated outer membrane protein of $A$. baumannii) [71] and the $43 \mathrm{kDa}$ protein, which exhibits homology with $0 \operatorname{prD}$ of $P$. aeruginosa [72]. It has been suggested that CarO may function as a carbapenem-nonspecific channel, while OprD-like porin may function as a carbapenem-specific channel [73]. Clinical outbreaks of carbapenem-resistant A. baumannii isolates have been described in association with porin loss, including loss other OMPs, such as 47-, 44-, and 37$\mathrm{kDa}$ OMPs in A. baumannii isolates in New York City [12], and loss of 22- and 33-kDa OMPs in association with OXA-24/40 in Spain [14]. 


\subsubsection{Multidrug efflux pumps}

While the outer membrane can limit the entry of antimicrobials into the bacterial cell, multidrug efflux pumps actively export multiple classes of antimicrobials from the cell [73]. While transport proteins involved in metabolic function exhibit a high degree of substrate specificity, multidrug efflux systems are more promiscuous [74]. Thus, efflux pumps work synergistically with the low permeability of the outer membrane [75]. Expression of efflux pumps is associated with an increased minimum inhibitory concentration (MIC) of many different antibiotic classes, including resistance to tigecycline, aminoglycosides and carbapenem in A. baumannii [76].

The major efflux pumps involved in multidrug resistance in A. baumannii belong to the group of proton-motive-force-dependent exporters, especially the major facilitator superfamily (MFS) and resistance-nodulation-cell division superfamily (RND) families [73]. Several MFS-family efflux pumps have been characterized in A. baumannii, including TetA, CmlA, MdfA, CraA and AmvA, which mediate resistance to different types of antibiotics (including $\beta$-lactams) [18]. An example of an RND family member is (chromosomally-encoded) AdeABC of $A$. baumannii, the best studied member, thus far. AdeABC overexpression is a major mechanism for decreased susceptibility to various antibiotic classes [76], and efflux inhibitors (e.g. phenyl-arginine- $\beta$ naphthylamide, carbonyl cyanide 3-chlorophenylhydrazone) have been shown to reverse resistance [77].

Since antibiotics act as AdeABC substrates, they can increase the expression of the AdeABC genes, which are chromosomally encoded, leading to multidrug resistance. Treatment failure and death due to A. baumannii infection are common when efflux pumps (especially the RND family) are implicated in antibiotic resistance [78]. In addition to the AdeABC efflux pump, other RNDtype efflux pumps, including AdeFGH [79] and AdeIJK [80], are implicated in multidrug resistance in $A$. baumannii.

\subsubsection{Penicillin-binding proteins}

Another relevant mechanism of resistance to $\beta$-lactams is direct modification of their targets: the penicillin-binding proteins (PBPs), which catalyse peptidoglycan synthesis and are associated with cell morphogenesis and the cell division complex [81]. $\beta$-Lactams are suicide inhibitors which bind covalently and irreversibly to PBPs [82]. There is limited information regarding this resistance mechanism in A. baumannii, but no differences were found between the sequences of susceptible and resistant $A$. baumannii strains [83]. Although confirmatory studies are required, this suggests that PBP mutations are not as important a resistance mechanism in A. baumannii as in other pathogens (e.g. P. Aeruginosa) [84]. 
However the impact of PBP alterations on bacterial virulence should be further investigated, as PBP7/8 contributes to both the in vitro and in vivo survival of A. baumannii. A PBP7/8 mutant strain exhibited poorer survival in in vivo models, compared to the isogenic wild-type strain [85].

\subsubsection{Resistance to $\beta$-lactamase inhibitors}

Most $\beta$-lactamase inhibitors are ineffective against $A$. baumannii: no commercial inhibitors exist with activity against its class $B$ and $D$ carbapenemases. An exception is sulbactam, which has affinity for $A$. baumannii's PBPs [13,86] and possesses bactericidal activity against $A$. baumannii. It is usually used in combination with ampicillin; however, the contribution of sulbactam is more relevant than the contribution of ampicillin as antimicrobial agent against this pathogen. While no breakpoints have been defined for $A$. baumannii, it is considered susceptible when MIC $\leq 4 \mathrm{mg} \mathrm{L}^{-1}$ [87]. Sulbactam monotherapy is not recommended in patients with serious infections, and resistance to sulbactam has already been described in Acinetobacter [87]. Reduced PBP2 expression is associated with resistance to this compound [13], although production of the non-ESBL $\beta$-lactamase TEM-1 has also been suggested to contribute to sulbactam resistance [88]. Clavulanic acid, too, shows bactericidal activity against a percentage of $A$. baumannii isolates [89]. New agents, which specifically inhibit $A$ baumannii $\beta$-lactamases, are being developed (e.g. ETX2514 [90] and LN-1-255 [60]), but additional preclinical assays are required to evaluate their in vivo efficacy.

\subsubsection{Resistance to aminoglycosides}

Aminoglycosides are effective against both Gram-negative and -positive pathogens. During A. baumannii infection, specifically, tobramycin and amikacin are used (in combination with other antimicrobials) [9]. Aminoglycoside antibiotics target ribosomal 16S rRNA, modifying its structure to produce a loss of translation fidelity, production of erroneous proteins, and, finally, bacterial cell death [91]. Bacteria exhibit increasing levels of resistance to aminoglycosides, mainly by acquiring genes encoding aminoglycosidemodifying enzymes (AME), $N$-acetyltransferases (AAC), phosphotransferases (APH) or $O$ - adenyltransferases (ANT), all of which are typically encoded by transposable elements. Other implicated mechanisms of resistance include mutation of ribosomal proteins or RNA. Ribosomal methylases - which methylate the aminoacyl site of $16 \mathrm{~S}$ rRNA - also confer high resistance to aminoglycosides, and six acquired 16S rRNA methyltransferases have been described: $\operatorname{arm} A, r m t A, r m t B, r m t C, r m t D$ and $r m t E$ [92]. An additional mechanism of aminoglycoside resistance is reduction of intracellular accumulation by means of outer membrane alterations, two-component systems and efflux pumps [e.g. the AbeM pump, a member of the multidrug and toxic compound extrusion (MATE) family] [93]. 
Many A. baumannii isolates express a combination of aminoglycosidemodifying enzymes [94,95]. A multidrug resistant $A$. baumannii isolate carrying genes for four aminoglycoside-modifying enzymes was described in China [96], and Japanese and Greek studies have shown that the majority of multidrug-resistant isolates carry at least one gene encoding an aminoglycoside-modifying enzyme [95,97]. In a 2007 outbreak of highly aminoglycoside-resistant $A$. baumannii isolates, the strains carried the genes for armA together with Per-1 and OXA-23 carbapenemases [23]. Similarly, multidrug-resistant $A$. baumannii isolates have been described that carry both a bla ${ }_{\text {OXA-23-like gene }\left(a a c\left(6^{\prime}\right)-I b\right)}$ and the $16 \mathrm{~S}$ rRNA methylase armA. Such isolates show that $A$. baumannii can employ multiple simultaneous mechanisms to elude the action of antimicrobials.

\subsubsection{Resistance to tigecycline}

Tigecycline is a relatively new broad-spectrum glycylcycline antibiotic, which has demonstrated in vitro and in vivo activity against A. baumannii [98]. It is a derivative of minocycline, with structural modifications that improve ribosomal binding-site affinity and orientation relative to both minocycline and tetracycline [99]. Tigecycline is one of the few agents developed recently that has enhanced activity against problematic Gram-negative organisms. In the 2005-2011 Tigecycline Evaluation and Surveillance Trial investigating multidrug-resistant $A$. baumannii strains, tigecycline's $\mathrm{MIC}_{50}$ was $0.5 \mathrm{mg} \mathrm{L}^{-1}$, and its $\mathrm{MIC}_{90}$ was $1 \mathrm{mg} \mathrm{L}^{-1}$ [100].

Tigecycline can often overcome active efflux and ribosomal protein resistance mechanisms which inactivate the tetracyclines $(\operatorname{tet}(\mathrm{A})$ to tet(E) efflux pump genes) [101]. However, resistance has been detected in some strains, due to high expression levels of chromosomally-encoded efflux pumps; tigecycline is susceptible to efflux by overexpressed multidrug efflux systems such as AdeABC and AdeIJK [101,102]. Several studies have already described high rates of tigecycline-resistant strains in A. baumannii [103,104], including development of resistance during tigecycline treatment [105]. However, little is known about the specific tigecycline resistance mechanisms of A. baumannii, necessitating further investigation.

\subsubsection{Resistance to polymyxins}

The increasingly frequent isolation of strains resistant to carbapenems, sulbactam, rifampin or tigecycline $[106,107]$ has driven the therapeutic use of polymyxins. Colistin and polymyxin $\mathrm{B}$ bind to the portion of the cell membrane interacting with the lipid A moiety of lipopolysaccharide (LPS) to cause outer membrane disorganization and hyper-permeability, leading to rapid Gramnegative bacterial death [108]. Colistin - discovered in the 1940s - was used mainly in the 1960s and 1970s, before being largely abandoned due to 
nephron- and neurotoxicity; recent studies have demonstrated that revised dosing regimens can minimize this problem [109].

Polymyxins are active against most $A$. baumannii isolates, though colistinresistant isolates have been described in vitro and in vivo [110-114]. For example, of the A. baumannii isolates recovered at two Korean hospitals, $30.6 \%$ exhibited colistin resistance [115], and outbreaks of polymyxinresistant $A$. baumannii have been already reported [116-118]. Two primary colistin-resistance mechanisms have been described in A. baumannii to date. The most common is modification of the lipid A moiety of LPS with phosphoethanolamine (PEtN) as a result of mutations in the $p m r A / p m r B$ twocomponent system [119]. The modifications of lipid A by the addition of PEtN confer a positive charge to LPS, preventing colistin binding. The mutations in pmrA or $p m r B$ induce expression of $p m r A$, in turn leading to up-regulated expression of the $\operatorname{pmrCAB}$ operon, and subsequent synthesis and addition of PEtN to the lipid A portion of LPS [119-121]. The second mechanism is the complete loss of lipopolysaccharide caused by either mutation or insertional inactivation of the lipid A biosynthesis genes. In colistin-resistant $A$. baumannii, mutations in lipid A biosynthesis genes $(\operatorname{lp} x A, \operatorname{lp} x C$ and $\operatorname{lp} x D)$ due to nucleotide substitution, deletion or insertional inactivation by sequence ISAba11, completely abrogate production of LPS with high colistin resistance (MIC > $128 \mathrm{mg} \mathrm{L}^{-1}$ ) $[113,122]$. Additionally, polymyxin B-resistant $A$. baumannii isolates have been shown to carry mutations in the $\operatorname{lp} x C$ and $\operatorname{lp} x D$ genes, in addition to mutations in the $\operatorname{lps} B$ gene which encodes a glycosyltransferase involved in LPS core biosynthsis [123]. However, colistin-resistant $A$. baumannii lpx mutants (lacking LPS) also demonstrate reduced virulence and fitness compared to colistin-resistant A. baumannii $p m r A / p m r B$ mutants (PEtN-modified LPSs) [124], indicating that Ipx mutation comes with a biological cost.

Other colistin-resistance mechanisms have been recently suggested, including modification of Gram-negative outer membrane asymmetric lipid distribution (essential for outer membrane functions) [125]. Also, two studies have suggested that efflux pumps may be involved in the colistin resistance phenotype in A. baumannii [126,127].

\subsection{VIRULENT AND MULTIDRUG-RESISTANT DISSEMINATED CLONES OF A. baumannii}

Multidrug-resistant microorganisms, such as A. baumannii, are opportunistic pathogens, able to compete in new niches where previously only commensals or non-pathogenic microorganisms existed. The ability to adapt to survival and persistence in nosocomial environments, encompassing patients with 
weakened immune systems and an environment with high antimicrobial pressure, has led to the emergence of $A$. baumannii as a key pathogen, whereas a few decades ago, it caused practically no disease. At least in these specific settings, the incidence of multidrug-resistant and virulent clones of $A$. baumannii is also increasing worldwide.

The population of clinical isolates of A. baumannii is dominated by three lineages: European or International clones I, II and III, corresponding to clonal complex 1 (CC1, comprising ST1, ST7, ST8, ST19 and ST20), clonal complex 2 (CC2, comprising ST2, ST45 and ST47) and clonal complex 3 (CC3, comprising ST3 and ST14) [128,129]. The predominance of a few successful multidrugresistant lineages worldwide underlines the importance of studying A. baumannii epidemiology.

Outbreaks are most frequently attributable to European clones I and II [130]. The evolutionary advantage of these predominant clones is due to their capacity for acquiring resistance determinants. Clone II is particularly welladapted to hospital environments [131], and CC2 is the most frequent genetic lineage observed in European, Asian and North American carbapenemresistant Acinetobacter isolates (with carbapenem resistance mainly mediated by class $D \beta$-lactamases such as OXA-23, OXA-24/40 and OXA-58, or relevant metallo- $\beta$-lactamase-type carbapenemase genes) [132-134]. Other CCs that exhibit narrower distribution patterns than European clones I-III do exist, such as clone ST15. The predominance and geographic distribution of certain clones is usually associated with their capacity to acquire multiple resistance mechanisms [128], either chromosomal or plasmid-encoded [135]. Regarding geographic distribution of acquired OXA genes, OXA-58-like genes are associated with Greece and Italy, OXA-24/40-like genes are associated with Spain and Portugal, and OXA-23-like genes are associated with Northern European countries, Asia and South America [129]. The ability of these clonal lineages to adapt and acquire these mechanisms is a key role in the successes of their distribution.

Frequently, internationally-distributed resistant clones demonstrate efficient pathogenic factors. For instance, an isolate carrying the OXA-23 carbapenemase gene, and belonging to international clone II, led to the death of a patient within only six days [136]. Some clones can cause outbreaks, rapidly affecting up to hundreds of patients. For example, the high-risk clone ST56, which is susceptible only to tigecycline and colistin, and carries the carbapenemase OXA-24/40, as well as overexpressing two putative virulence factors (septicolysin and the TonB-dependent receptor). This strain spread extremely rapidly, causing the largest nosocomial outbreak ever reported, with 377 patients becoming colonized or infected with A. baumannii [137].

While $\beta$-lactamase-mediated resistance to $\beta$-lactams is of great therapeutic concern, few studies have analysed the impact of these enzymes on $A$. baumannii virulence. There is, however, a relationship between carrying 
carbapenemase PER-1 and increased cell adhesion in A. baumannii strains, although the exact mechanism of the association remains unknown [138]. Other resistance factors are also implicated in virulence. Porins, for example, provide trans-membrane passage for molecules, such as nutrients, toxins and antibiotics, and have clear roles in both virulence and resistance [139]. Furthermore, the A. baumannii OmpA (HMP-AB) protein, which has been associated with cephalosporin resistance [140], has also been reported to induce human epithelial and dendritic cell death via mitochondrial targeting [141], and is involved in biofilm formation [142]. The 0mp33-36 protein of $A$. baumannii, involved in carbapenem resistance, has also been suggested to be involved in apoptosis and modulation of autophagy [143]. Moreover, both CarO and Omp33-36 porins are implicated in biofilm formation [144], and both OmpA and Omp33-36 proteins (as well as the TonB-dependent copper receptor) are fibronectin-binding proteins (FBPs) [145].

\subsection{ANTIMICROBIAL RESISTANCE AND VIRULENCE MECHANISM CO-SELECTION}

A. baumannii is naturally competent at incorporating DNA from other bacterial species [19]. It is commonly-known that the horizontal transfer of multiple resistance genes can occur simultaneously. Similarly, horizontal transfer is a relevant mechanism to exchange virulence factors. The co-selection of virulence and resistance factors has been observed during pathogen evolution in the post-antibiotic era, and could contribute to bacterial adaptation to new environments. The distribution of such transfer elements (e.g. plasmids, integrons and transposons) in pathogens, such as Acinetobacter, may become a major clinical challenge in the future.

Plasmids are extra-chromosomal, self-replicating elements, which are nonessential and are usually implicated in functions, such as virulence, resistance or persistence under extreme conditions [3]. Conjugative plasmids have a relevant role in the evolution of $A$. baumannii due to their horizontal transmission, including resistance genes (mainly during the last decades), highlighting the key role of the plasmids [146,147]. Evidence suggests that $A$. baumannii strains may bear distinct sets of plasmid types and thus a broad heterogeneity of resistance plasmids [148,149]. An example of virulence and resistance co-selection in A. baumannii has been described in clone ST56, which caused a large 2006 outbreak in a Spanish hospital. The plasmid pMMA2, isolated from the main outbreak clone, harboured the bla $a_{\text {OXA-24/40 }}$ gene, as well as two genes implicated in virulence (a septicolysin-like gene encoding a pore-forming toxin, and a TonB-dependent receptor gene encoding an outer membrane protein involved in iron uptake) [137]. 
Genetic elements associated with antibiotic resistance gene acquisition by Acinetobacter include integrons and transposons. Integrons contain sitespecific recombination systems through which they can include resistance genes, and transposons are able to integrate and move genes. These structures are usually found as part of the chromosome or plasmids [150-152]. There is a high prevalence of class 1 and 2 integrons in A. baumannii [153,154]. Most acquired MBL genes in $A$. baumannii occur within class 1 integrons, which often contain several resistance genes. Many genes encoding aminoglycosidemodifying enzymes are associated with transposons. Moreover, transposons can concomitantly carry other resistance determinants [24].

IS elements, too, play an important role in A. baumannii resistance. ISAba1, ISAba2, ISAba3, ISAba4 and IS18 are associated with carbapenemase gene expression in A. baumannii. As intimated above, ISAba1 is the most highlyprevalent such element of this pathogen [155]. Frequently, IS element-encoded promoter regions increase expression of genes such as $b l a_{\text {OXA-23-like, }} b l a_{\text {OXA-51- }}$ like, $b l a_{0 X A-58}$-like and $b l a_{\text {AmpC }}[151]$.

Gram-negative bacilli secrete vesicles, which mediate interactions with other bacteria and eukaryotic cells in the local environment. The A. baumannii secretome is also implicated in both virulence and resistance; two examples of outer membrane vesicles (OMVs) of the secretion systems transporting virulence and resistance factors have been described. OMV-mediated toxin delivery is a potent virulence mechanism employed by various Gram-negative organisms. The OMVs can thus be employed as a means to deliver virulence factors, and it appears they may also be relevant to transmission of resistance genes in A. baumannii. The release of OMVs favours the spread of antibiotic resistance genes to other bacteria via horizontal DNA transfer (e.g. transmission of OMVs harbouring the bla $a_{\mathrm{OXA}-24 / 40}$ carbapenemase gene in an $A$. baumannii isolate). Furthermore, the A. baumannii ATCC 17978 strain, transformed with OMVs from clinical strains, exhibits an antibiotic-resistant profile due to expression of OXA-24/40 carbapenemase. Thus, in A. baumannii, OMVs represent a new mechanism of antibiotic resistance gene dissemination, in addition to the previously-known mechanisms (conjugation, transformation, and transduction) [156].

Lastly, some Gram-negative bacteria utilize the antibacterial type VI secretion system (T6SS) to kill competitors. In A. baumannii strains, T6SS exhibits variable expression, including a self-transmissible plasmid that carries T6SS negative regulators, as well as resistance factors. This secretion system is inactivated in resistant cells, but some cells lose this plasmid, thereby derepressing expression of the secretion system and T6SS-mediated killing of the rest of surrounding microflora. In this way, harbouring of resistance genes can lead to elimination of competing bacteria [157]. 


\subsection{CONCLUDING REMARKS}

This review highlights the major resistance mechanisms of $A$. baumannii, and their role in the spread of this organism. Future considerations include the urgent requirement for new antibiotics to treat emerging bacteria that are resistant to almost all existing (including last-resort) antibiotics. Very few truly new antibiotics have been developed against such Gram-negative pathogens that have emerged since the 1990s. Development of new antibacterial therapies need not be limited to antibiotics; innovative anti-virulence therapies (including novel vaccines and the revival of antibacterial phage therapy) are a promising alternative to antibiotic treatment in combating resistant and/or virulent pathogens.

\section{ACKNOWLEGMENTS}

This work has been supported by projects CP13/00226, P14/00059, and PI17/01482 all integrated in the National Plan for Scientific Research, Development and Technological Innovation and funded by the ISCIII - General Subdirection of Assessment and Promotion of the Research-European Regional Development Fund (FEDER) "A way of making Europe". Also has been supported by Spanish Network for Research in Infectious Diseases (REIPI RD16/0016/006).

\section{REFERENCES}

1. Antimicrobial Resistance: Tackling a crisis for the health and wealth of nations. Review on Antimicrobial Resistance, https://amrreview.org/sites/default/files/AMR\%20Review\%20Paper\%20\%20Tackling\%20a\%20crisis\%20for $\% 20$ the $\% 20$ health $\% 20$ and $\% 20$ wealth $\%$ 20of\%20nations_1.pdf (15-May-2018).

2. Global priority list of antibiotic-resistant bacteria to guide research, discovery and development of new antibiotics. World Health Organization, 2017, http://www.who.int/medicines/publications/WHO-PPLShort_Summary_25Feb-ET_NM_WHO.pdf (15-May-2018).

3. A. Beceiro, M. Tomás, G. Bou, Clin. Microbiol. Rev. 26 (2013) 185-230.

4. H. Giamarellou, Int. J. Antimicrob. Agents 36(2) (2010) S50-S54.

5. D. Wong, T.B. Nielsen, R.A. Bonomo, P. Pantapalangkoor, B. Luna, B. Spellberg, Clin. Microbiol. Rev. 30 (2017) 409-447.

6. A.C. Gales, R.N. Jones, H.S. Sader, J. Antimicrob. Chemother. 66 (2011) 20702074.

7. M. Villar, M.E. Cano, E. Gato, J. Garnacho-Montero, J. Miguel Cisneros, C. Ruíz de Alegría, F. Fernández-Cuenca, L. Martínez-Martínez, J. Vila, A. Pascual, M. 
Tomás, G. Bou, J. Rodríguez-Baño, G.G.R.-A. Group, Medicine (Baltimore) 93 (2014) 202-210.

8. A.Y. Peleg, H. Seifert, D.L. Paterson, Clin. Microbiol. Rev. 21 (2008) 538-582.

9. L.L. Maragakis, T.M. Perl, Clin. Infect. Dis. 46 (2008) 1254-1263.

10. D.I. Andersson, D. Hughes, FEMS Microbiol. Rev. 35 (2011) 901-911.

11. A. Jawad, H. Seifert, A.M. Snelling, J. Heritage, P.M. Hawkey, J. Clin. Microbiol. 36 (1998) 1938-1941.

12. J. Quale, S. Bratu, D. Landman, R. Heddurshetti, Clin. Infect. Dis. 37 (2003) 214220.

13. F. Fernández-Cuenca, L. Martínez-Martínez, M.C. Conejo, J.A. Ayala, E.J. Perea, A. Pascual, J. Antimicrob. Chemother. 51 (2003) 565-574.

14. G. Bou, G. Cerveró, M.A. Domínguez, C. Quereda, J. Martínez-Beltrán, J. Clin. Microbiol. 38 (2000) 3299-3305.

15. G.A. Jacoby, Clin. Infect. Dis. 41(2) (2005) S120-S126.

16. M.J. McConnell, L. Actis, J. Pachón, FEMS Microbiol. Rev. 37 (2013) 130-155

17. J.H. Jeon, J.H. Lee, J.J. Lee, K.S. Park, A.M. Karim, C.R. Lee, B.C. Jeong, S.H. Lee, Int. J. Mol. Sci. 16 (2015) 9654-9692.

18. M.F. Lin, C.Y. Lan, World J. Clin. Cases 2 (2014) 787-814.

19. C.R. Lee, J.H. Lee, M. Park, K.S. Park, I.K. Bae, Y.B. Kim, C.J. Cha, B.C. Jeong, S.H. Lee, Front. Cell. Infect. Microbiol. 7 (2017) 55.

20. N. Nagano, Y. Nagano, C. Cordevant, N. Shibata, Y. Arakawa, J. Clin. Microbiol. 42 (2004) 3978-3984.

21. A. Potron, L.S. Munoz-Price, P. Nordmann, T. Cleary, L. Poirel, Antimicrob. Agents Chemother. 55 (2011) 5946-5948.

22. L. Poirel, O. Menuteau, N. Agoli, C. Cattoen, P. Nordmann, J. Clin. Microbiol. 41 (2003) 3542-3547.

23. J.W. Kim, S.T. Heo, J.S. Jin, C.H. Choi, Y.C. Lee, Y.G. Jeong, S.J. Kim, J.C. Lee, Clin. Microbiol. Infect. 14 (2008) 716-718.

24. K. Lee, D. Yong, S.H. Jeong, Y. Chong, Yonsei Med. J. 52 (2011) 879-891.

25. C. Moubareck, S. Brémont, M.C. Conroy, P. Courvalin, T. Lambert, Antimicrob. Agents Chemother. 53 (2009) 3579-3581.

26. P. Bogaerts, T. Naas, F. El Garch, G. Cuzon, A. Deplano, T. Delaire, T.D. Huang, B. Lissoir, P. Nordmann, Y. Glupczynski, Antimicrob. Agents Chemother. 54 (2010) 4872-4878.

27. K.M. Hujer, A.M. Hujer, E.A. Hulten, S. Bajaksouzian, J.M. Adams, C.J. Donskey, D.J. Ecker, C. Massire, M.W. Eshoo, R. Sampath, J.M. Thomson, P.N. Rather, D.W. Craft, J.T. Fishbain, A.J. Ewell, M.R. Jacobs, D.L. Paterson, R.A. Bonomo, Antimicrob. Agents Chemother. 50 (2006) 4114-4123.

28. J. Vila, A. Marcos, F. Marco, S. Abdalla, Y. Vergara, R. Reig, R. Gomez-Lus, T. Jimenez de Anta, Antimicrob. Agents Chemother. 37 (1993) 138-141.

29. K. Bush, G.A. Jacoby, Antimicrob. Agents Chemother. 54 (2010) 969-976.

30. G. Cornaglia, H. Giamarellou, G.M. Rossolini, Lancet Infect. Dis. 11 (2011) 381393.

31. J.H. Yum, K. Yi, H. Lee, D. Yong, K. Lee, J.M. Kim, G.M. Rossolini, Y. Chong, J. Antimicrob. Chemother. 49 (2002) 837-840.

32. K. Lee, J.H. Yum, D. Yong, H.M. Lee, H.D. Kim, J.D. Docquier, G.M. Rossolini, Y. Chong, Antimicrob. Agents Chemother. 49 (2005) 4485-4491.

33. R.A. Bonnin, L. Poirel, T. Naas, M. Pirs, K. Seme, J. Schrenzel, P. Nordmann, Clin. Microbiol. Infect. 18 (2012) E362-365. 
34. Y. Chen, Z. Zhou, Y. Jiang, Y. Yu, J. Antimicrob. Chemother. 66 (2011) 12551259.

35. P. Espinal, G. Fugazza, Y. López, M. Kasma, Y. Lerman, S. Malhotra-Kumar, H. Goossens, Y. Carmeli, J. Vila, Antimicrob. Agents. Chemother. 55 (2011) 53965398.

36. Y. Pfeifer, G. Wilharm, E. Zander, T.A. Wichelhaus, S. Göttig, K.P. Hunfeld, H. Seifert, W. Witte, P.G. Higgins, J. Antimicrob. Chemother. 66 (2011) 1998-2001.

37. S. Chatterjee, S. Datta, S. Roy, L. Ramanan, A. Saha, R. Viswanathan, T. Som, S. Basu, Front. Microbiol. 7 (2016) 1126.

38. Y.C. Lin, K.C. Hsia, Y.C. Chen, W.H. Sheng, S.C. Chang, M.H. Liao, S.Y. Li, Antimicrob. Agents Chemother. 54 (2010) 2078-2084.

39. J.H. Lee, C.H. Choi, H.Y. Kang, J.Y. Lee, J. Kim, Y.C. Lee, S.Y. Seol, D.T. Cho, K.W. Kim, D.Y. Song, J.C. Lee, J. Antimicrob. Chemother. 59 (2007) 633-639.

40. A. Beceiro, G. Bou, Class C $\beta$-Lactamases: an increasing problem worldwide. Reviews in Medical Microbiology, pp. 141-152.

41. G. Bou, J. Martínez-Beltrán, Antimicrob. Agents Chemother. 44 (2000) 428-432.

42. N.C. Gordon, D.W. Wareham, Int. J. Antimicrob. Agents 35 (2010) 219-226.

43. A. Beceiro, A. Pérez, F. Fernández-Cuenca, L. Martínez-Martínez, A. Pascual, J. Vila, J. Rodríguez-Baño, J.M. Cisneros, J. Pachón, G. Bou, Antimicrob. Agents Chemother. 53 (2009) 1177-1184.

44. A. Pérez, F.J. Pérez-Llarena, P. García, F. Kerff, A. Beceiro, M. Galleni, G. Bou, J. Antimicrob. Chemother. 69 (2014) 2407-2411.

45. K.M. Hujer, N.S. Hamza, A.M. Hujer, F. Perez, M.S. Helfand, C.R. Bethel, J.M. Thomson, V.E. Anderson, M. Barlow, L.B. Rice, F.C. Tenover, R.A. Bonomo, Antimicrob. Agents Chemother. 49 (2005) 2941-2948.

46. https://www.ncbi.nlm.nih.gov/bioproject/PRJNA313047.

47. C. Héritier, L. Poirel, P. Nordmann, Clin. Microbiol. Infect. 12 (2006) 123-130.

48. H. Segal, E.C. Nelson, B.G. Elisha, Antimicrob. Agents Chemother. 48 (2004) 612-614.

49. K.C. Kaitany, N.V. Klinger, C.M. June, M.E. Ramey, R.A. Bonomo, R.A. Powers, D.A. Leonard, Antimicrob. Agents Chemother. 57 (2013) 4848-4855.

50. F. Perez, A.M. Hujer, K.M. Hujer, B.K. Decker, P.N. Rather, R.A. Bonomo, Antimicrob. Agents Chemother. 51 (2007) 3471-3484.

51. J. Walther-Rasmussen, N. Hoiby, J. Antimicrob. Chemother. 57 (2006) 373-383.

52. L. Poirel, P. Nordmann, Clin. Microbiol. Infect. 12 (2006) 826-836.

53. D.A. Leonard, R.A. Bonomo, R.A. Powers, Acc. Chem. Res. 46 (2013) 2407-2415.

54. R. Paton, R.S. Miles, J. Hood, S.G. Amyes, Int. J. Antimicrob. Agents 2 (1993) 8187.

55. R. Zarrilli, M. Giannouli, F. Tomasone, M. Triassi, A. Tsakris, J. Infect. Dev. Ctries 3 (2009) 335-341.

56. K. Lee, M.N. Kim, T.Y. Choi, S.E. Cho, S. Lee, D.H. Whang, D. Yong, Y. Chong, N. Woodford, D.M. Livermore, K. Group, Int. J. Antimicrob. Agents 33 (2009) 520524.

57. P.G. Higgins, F.J. Pérez-Llarena, E. Zander, A. Fernández, G. Bou, H. Seifert, Antimicrob. Agents Chemother. 57 (2013) 2121-2126.

58. $\quad$ L. Poirel, T. Naas, P. Nordmann, Antimicrob. Agents Chemother. 54 (2010) 2438.

59. B.A. Evans, S.G. Amyes, Clin. Microbiol. Rev. 27 (2014) 241-263. 
60. J.C. Vázquez-Ucha, M. Maneiro, M. Martínez-Guitián, J. Buynak, C.R. Bethel, R.A. Bonomo, G. Bou, M. Poza, C. González-Bello, A. Beceiro, Antimicrob. Agents Chemother. 61 (2017).

61. P.D. Mugnier, L. Poirel, T. Naas, P. Nordmann, Emerg. Infect. Dis. 16 (2010) 3540.

62. C.A. Smith, N.T. Antunes, N.K. Stewart, H. Frase, M. Toth, K.A. Kantardjieff, S. Vakulenko, ACS Chem. Biol. 10 (2015) 1791-1796.

63. J.F. Turton, M.E. Ward, N. Woodford, M.E. Kaufmann, R. Pike, D.M. Livermore, T.L. Pitt, FEMS Microbiol. Lett. 258 (2006) 72-77.

64. G. Bou, A. Oliver, J. Martínez-Beltrán, Antimicrob. Agents Chemother. 44 (2000) 1556-1561.

65. M. Afzal-Shah, N. Woodford, D.M. Livermore, Antimicrob. Agents Chemother. 45 (2001) 583-588.

66. L. Poirel, S. Marqué, C. Héritier, C. Segonds, G. Chabanon, P. Nordmann, Antimicrob. Agents Chemother. 49 (2005) 202-208.

67. S. Martí, J. Sánchez-Céspedes, E. Oliveira, D. Bellido, E. Giralt, J. Vila, Proteomics 6(1) (2006) S82-S87.

68. M. Obara, T. Nakae, J. Antimicrob. Chemother. 28 (1991) 791-800.

69. A. Gribun, Y. Nitzan, I. Pechatnikov, G. Hershkovits, D.J. Katcoff, Curr. Microbiol. 47 (2003) 434-443.

70. M. del Mar Tomás, A. Beceiro, A. Pérez, D. Velasco, R. Moure, R. Villanueva, J. Martínez-Beltrán, G. Bou, Antimicrob. Agents Chemother. 49 (2005) 51725175.

71. A. Siroy, V. Molle, C. Lemaître-Guillier, D. Vallenet, M. Pestel-Caron, A.J. Cozzone, T. Jouenne, E. Dé, Antimicrob. Agents Chemother. 49 (2005) 48764883.

72. M. Dupont, J.M. Pagès, D. Lafitte, A. Siroy, C. Bollet, J. Proteome Res. 4 (2005) 2386-2390.

73. J. Vila, S. Martí, J. Sánchez-Céspedes, J. Antimicrob. Chemother. 59 (2007) 1210-1215.

74. P.J. Henderson, C.K. Hoyle, A. Ward, Biochem. Soc. Trans. 28 (2000) 513-517.

75. K. Poole, Curr. Pharm. Biotechnol. 3 (2002) 77-98.

76. S. Coyne, P. Courvalin, B. Périchon, Antimicrob. Agents Chemother. 55 (2011) 947-953.

77. J. Cortez-Cordova, A. Kumar, Int. J. Antimicrob. Agents 37 (2011) 420-424.

78. P. Wieczorek, P. Sacha, T. Hauschild, M. Zórawski, M. Krawczyk, E. Tryniszewska, Folia Histochem. Cytobiol. 46 (2008) 257-267.

79. S. Coyne, N. Rosenfeld, T. Lambert, P. Courvalin, B. Périchon, Antimicrob. Agents Chemother. 54 (2010) 4389-4393.

80. P.F. Hou, X.Y. Chen, G.F. Yan, Y.P. Wang, C.M. Ying, Chemotherapy 58 (2012) 152-158.

81. E. Sauvage, F. Kerff, M. Terrak, J.A. Ayala, P. Charlier, FEMS Microbiol. Rev. 32 (2008) 234-258.

82. C. Goffin, J.M. Ghuysen, Microbiol. Mol. Biol. Rev. 62 (1998) 1079-1093.

83. R. Cayô, M.C. Rodríguez, P. Espinal, F. Fernández-Cuenca, A.A. Ocampo-Sosa, A. Pascual, J.A. Ayala, J. Vila, L. Martínez-Martínez, Antimicrob. Agents Chemother. 55 (2011) 5907-5913.

84. B. Moyá, A. Beceiro, G. Cabot, C. Juan, L. Zamorano, S. Alberti, A. Oliver, Antimicrob. Agents Chemother. 56 (2012) 4771-4778. 
85. T.A. Russo, U. MacDonald, J.M. Beanan, R. Olson, I.J. MacDonald, S.L. Sauberan, N.R. Luke, L.W. Schultz, T.C. Umland, J. Infect. Dis. 199 (2009) 513-521.

86. P.I. Rafailidis, E.N. Ioannidou, M.E. Falagas, Drugs 67 (2007) 1829-1849.

87. F. Fernández-Cuenca, M. Tomás-Carmona, F. Caballero-Moyano, G. Bou, L. Martínez-Martínez, J. Vila, J. Pachón, J.M. Cisneros, J. Rodríguez-Baño, A. Pascual, Enferm. Infecc. Microbiol. Clin. 31 (2013) 4-9.

88. L. Krizova, L. Poirel, P. Nordmann, A. Nemec, J. Antimicrob. Chemother. 68 (2013) 2786-2791.

89. A. Beceiro, R. López-Rojas, J. Domínguez-Herrera, F. Docobo-Pérez, G. Bou, J. Pachón, Antimicrob. Agents Chemother. 53 (2009) 4298-4304.

90. T.F. Durand-Réville, S. Guler, J. Comita-Prevoir, B. Chen, N. Bifulco, H. Huynh, S. Lahiri, A.B. Shapiro, S.M. McLeod, N.M. Carter, S.H. Moussa, C. Velez-Vega, N.B. Olivier, R. McLaughlin, N. Gao, J. Thresher, T. Palmer, B. Andrews, R.A. Giacobbe, J.V. Newman, D.E. Ehmann, B. de Jonge, J. O'Donnell, J.P. Mueller, R.A. Tommasi, A.A. Miller, Nat. Microbiol. 2 (2017) 17104.

91. B. Gutierrez, J.A. Escudero, A. San Millan, L. Hidalgo, L. Carrilero, C.M. Ovejero, A. Santos-Lopez, D. Thomas-Lopez, B. Gonzalez-Zorn, Antimicrob. Agents Chemother. 56 (2012) 2335-2341.

92. K. Poole, Antimicrob. Agents Chemother. 49 (2005) 479-487.

93. X.Z. Su, J. Chen, T. Mizushima, T. Kuroda, T. Tsuchiya, Antimicrob. Agents Chemother. 49 (2005) 4362-4364.

94. L. Gallego, K.J. Towner, J. Med. Microbiol. 50 (2001) 71-77.

95. A. Nemec, L. Dolzani, S. Brisse, P. van den Broek, L. Dijkshoorn, J. Med. Microbiol. 53 (2004) 1233-1240.

96. J. Zhu, C. Wang, J. Wu, R. Jiang, Z. Mi, Z. Huang, J. Hosp. Infect. 73 (2009) 184185.

97. Y. Doi, J. Wachino, K. Yamane, N. Shibata, T. Yagi, K. Shibayama, H. Kato, Y. Arakawa, Antimicrob. Agents Chemother. 48 (2004) 2075-2080.

98. K.B. Anthony, N.O. Fishman, D.R. Linkin, L.B. Gasink, P.H. Edelstein, E. Lautenbach, Clin. Infect. Dis. 46 (2008) 567-570.

99. G. Bauer, C. Berens, S.J. Projan, W. Hillen, J. Antimicrob. Chemother. 53 (2004) 592-599.

100. D.L. Paterson, Y. Doi, Clin. Infect. Dis. 45 (2007) 1179-1181.

101. M.E. Falagas, P.K. Koletsi, I.A. Bliziotis, J. Med. Microbiol. 55 (2006) 1619-1629.

102. A. Ruzin, D. Keeney, P.A. Bradford, J. Antimicrob. Chemother. 59 (2007) 10011004.

103. Y.K. Park, J.Y. Choi, J.H. Song, K.S. Ko, Int. J. Antimicrob. Agents 33 (2009) 289290.

104. L.A. Arroyo, I. Mateos, V. González, J. Aznar, Antimicrob. Agents Chemother. 53 (2009) 1295-1296.

105. A.Y. Peleg, B.A. Potoski, R. Rea, J. Adams, J. Sethi, B. Capitano, S. Husain, E.J. Kwak, S.V. Bhat, D.L. Paterson, J. Antimicrob. Chemother. 59 (2007) 128-131.

106. C. Héritier, L. Poirel, T. Lambert, P. Nordmann, Antimicrob. Agents Chemother. 49 (2005) 3198-3202.

107. J. Vila, J. Pachón, Expert Opin. Pharmacother. 9 (2008) 587-599.

108. J.M. Cisneros-Herreros, J. Garnacho-Montero, M.E. Pachón-Ibáñez, Enferm. Infecc. Microbiol. Clin. 23(3) (2005) 46-51.

109. J. Li, R.L. Nation, R.W. Milne, J.D. Turnidge, K. Coulthard, Int. J. Antimicrob. Agents 25 (2005) 11-25. 
110. Y. Cai, D. Chai, R. Wang, B. Liang, N. Bai, J. Antimicrob. Chemother. 67 (2012) 1607-1615.

111. J.S. Hawley, C.K. Murray, J.H. Jorgensen, Antimicrob. Agents Chemother, 52 (2008) 351-352.

112. C.H. Tan, J. Li, R.L. Nation, Antimicrob. Agents Chemother. 51 (2007) 34133415.

113. J.H. Moffatt, M. Harper, P. Harrison, J.D. Hale, E. Vinogradov, T. Seemann, R. Henry, B. Crane, F. St Michael, A.D. Cox, B. Adler, R.L. Nation, J. Li, J.D. Boyce, Antimicrob. Agents Chemother. 54 (2010) 4971-4977.

114. S. Pournaras, A. Poulou, K. Dafopoulou, Y.N. Chabane, I. Kristo, D. Makris, J. Hardouin, P. Cosette, A. Tsakris, E. Dé, Antimicrob. Agents Chemother. 58 (2014) 828-832.

115. K.S. Ko, J.Y. Suh, K.T. Kwon, S.I. Jung, K.H. Park, C.I. Kang, D.R. Chung, K.R. Peck, J.H. Song, J. Antimicrob Chemother. 60 (2007) 1163-1167.

116. M. Fernández-Reyes, M. Rodríguez-Falcón, C. Chiva, J. Pachón, D. Andreu, L. Rivas, Proteomics 9 (2009) 1632-1645.

117. S. Quinteira, F. Grosso, H. Ramos, L. Peixe, Antimicrob. Agents Chemother. 51 (2007) 3465-3466.

118. J.R. Tuckerman, G. Gonzalez, M.A. Gilles-Gonzalez, J. Mol. Biol. 308 (2001) 449455.

119. A. Beceiro, E. Llobet, J. Aranda, J.A. Bengoechea, M. Doumith, M. Hornsey, H. Dhanji, H. Chart, G. Bou, D.M. Livermore, N. Woodford, Antimicrob. Agents Chemother. 55 (2011) 3370-3379.

120. E. Lesho, E.J. Yoon, P. McGann, E. Snesrud, Y. Kwak, M. Milillo, F. Onmus-Leone, L. Preston, K. St Clair, M. Nikolich, H. Viscount, G. Wortmann, M. Zapor, C. Grillot-Courvalin, P. Courvalin, R. Clifford, P.E. Waterman, J. Infect. Dis. 208 (2013) 1142-1151.

121. L.A. Arroyo, C.M. Herrera, L. Fernandez, J.V. Hankins, M.S. Trent, R.E. Hancock, Antimicrob. Agents Chemother. 55 (2011) 3743-3751.

122. J.H. Moffatt, M. Harper, B. Adler, R.L. Nation, J. Li, J.D. Boyce, Antimicrob. Agents Chemother. 55 (2011) 3022-3024.

123. S.S. Lean, Z. Suhaili, S. Ismail, N.I. Rahman, N. Othman, F.H. Abdullah, Z. Jusoh, C.C. Yeo, K.L. Thong, ISRN Microbiol. 2014 (2014) 953417.

124. A. Beceiro, A. Moreno, N. Fernandez, J.A. Vallejo, J. Aranda, B. Adler, M. Harper, J.D. Boyce, G. Bou, Antimicrob. Agents Chemother. 58 (2014) 518-526.

125. N. Thi Khanh Nhu, D.W. Riordan, T. Do Hoang Nhu, D.P. Thanh, G. Thwaites, N.P. Huong Lan, B.W. Wren, S. Baker, R.A. Stabler, Sci. Rep. 6 (2016) 28291.

126. M.I. Hood, A.C. Jacobs, K. Sayood, P.M. Dunman, E.P. Skaar, Antimicrob. Agents Chemother. 54 (2010) 1029-1041.

127. W. Ni, Y. Li, J. Guan, J. Zhao, J. Cui, R. Wang, Y. Liu, Antimicrob. Agents Chemother. 60 (2016) 3215-3218.

128. L. Diancourt, V. Passet, A. Nemec, L. Dijkshoorn, S. Brisse, PLoS One 5 (2010) e10034.

129. N. Woodford, J.F. Turton, D.M. Livermore, FEMS Microbiol. Rev. 35 (2011) 736755.

130. S.G. Bartual, H. Seifert, C. Hippler, M.A. Luzon, H. Wisplinghoff, F. RodríguezValera, J. Clin. Microbiol. 43 (2005) 4382-4390.

131. R. Zarrilli, S. Pournaras, M. Giannouli, A. Tsakris, Int. J. Antimicrob. Agents 41 (2013) 11-19. 
132. Y. Fu, J. Zhou, H. Zhou, Q. Yang, Z. Wei, Y. Yu, L. Li, J. Antimicrob. Chemother. 65 (2010) 644-650.

133. A. Nemec, L. Krízová, M. Maixnerová, L. Diancourt, T.J. van der Reijden, S. Brisse, P. van den Broek, L. Dijkshoorn, J. Antimicrob. Chemother. 62 (2008) 484-489.

134. F. Donnarumma, S. Sergi, C. Indorato, G. Mastromei, R. Monnanni, P. Nicoletti, P. Pecile, D. Cecconi, R. Mannino, S. Bencini, R. Fanci, A. Bosi, E. Casalone, J. Clin. Microbiol. 48 (2010) 1297-1304.

135. P.G. Higgins, C. Dammhayn, M. Hackel, H. Seifert, J. Antimicrob. Chemother. 65 (2010) 233-238.

136. G. Patel, F. Perez, A.M. Hujer, S.D. Rudin, J.J. Augustine, G.H. Jacobs, M.R. Jacobs, R.A. Bonomo, Transpl. Infect. Dis. 17 (2015) 289-296.

137. J. Acosta, M. Merino, E. Viedma, M. Poza, F. Sanz, J.R. Otero, F. Chaves, G. Bou, Emerg. Infect. Dis. 17 (2011) 1064-1067.

138. L.A. Sechi, A. Karadenizli, A. Deriu, S. Zanetti, F. Kolayli, E. Balikci, H. Vahaboglu, Med. Sci. Monit. 10 (2004) BR180-184.

139. A. Beceiro, M. Tomas, G. Bou, Clin. Microbiol. Rev. 26 (2013) 185-230.

140. E. Sugawara, H. Nikaido, J. Bacteriol. 194 (2012) 4089-4096.

141. J.S. Lee, C.H. Choi, J.W. Kim, J.C. Lee, J. Microbiol. 48 (2010) 387-392.

142. J.A. Gaddy, A.P. Tomaras, L.A. Actis, Infect. Immun. 77 (2009) 3150-3160.

143. Y. Smani, J. Dominguez-Herrera, J. Pachón, J. Infect. Dis. 208 (2013) 15611570.

144. M.P. Cabral, N.C. Soares, J. Aranda, J.R. Parreira, C. Rumbo, M. Poza, J. Valle, V. Calamia, I. Lasa, G. Bou, J. Proteome Res. 10 (2011) 3399-3417.

145. Y. Smani, M.J. McConnell, J. Pachón, PLoS One 7 (2012) e33073.

146. $\quad$ N. Datta, V.M. Hughes, Nature 306 (1983) 616-617.

147. V.M. Hughes, N. Datta, Nature 302 (1983) 725-726.

148. A. Bertini, L. Poirel, P.D. Mugnier, L. Villa, P. Nordmann, A. Carattoli, Antimicrob. Agents Chemother. 54 (2010) 4168-4177.

149. P. Nowak, P. Paluchowska, Folia Histochem. Cytobiol. 54 (2016) 61-74.

150. L. Poirel, R.A. Bonnin, P. Nordmann, IUBMB Life 63 (2011) 1061-1067.

151. M. Pagano, A.F. Martins, A.L. Barth, Braz. J. Microbiol. 47 (2016) 785-792.

152. A. Potron, L. Poirel, P. Nordmann, Int. J. Antimicrob. Agents 45 (2015) 568-585.

153. M.R. Gillings, Microbiol. Mol. Biol. Rev. 78 (2014) 257-277.

154. J.F. Turton, M.E. Kaufmann, J. Glover, J.M. Coelho, M. Warner, R. Pike, T.L. Pitt, J. Clin. Microbiol. 43 (2005) 3074-3082.

155. P. Villalón, S. Valdezate, M.J. Medina-Pascual, G. Carrasco, A. Vindel, J.A. SaezNieto, J. Antimicrob. Chemother. 68 (2013) 550-553.

156. C. Rumbo, E. Fernández-Moreira, M. Merino, M. Poza, J.A. Mendez, N.C. Soares, A. Mosquera, F. Chaves, G. Bou, Antimicrob. Agents Chemother. 55 (2011) 3084-3090.

157. B.S. Weber, P.M. Ly, J.N. Irwin, S. Pukatzki, M.F. Feldman, Proc. Natl. Acad. Sci. U $S A 112$ (2015) 9442-9447.

(C)2018 by the authors; licensee IAPC, Zagreb, Croatia. This chapter is an open-access publication distributed under the terms and conditions of the Creative Commons Attribution license (http://creativecommons.org/licenses/by/3.0/) (cc) EY 